\title{
Нейровизуализация
} при проведении ботулинотерапии

\author{
Мисиков В.К. • Степанова Е.А. • Остапчук К.А. • Сидорович В.И.
}

Приведено описание клинического случая - синдрома грушевидной мышцы у больного с люмбоишиалгией. Описана техника проведения ботулинотерапии данному больному под контролем нейровизуализации - рентгеновской компьютерной томографии области таза, что позволило точно осуществить инъекцию ботулотоксина в глубоко расположенную мышцу. Показана неточность определения места инъекции по наружным ориентирам.

Ключевые слова: синдром грушевидной мышцы, рентгеновская компьютерная томография, ботулотоксин.

\section{Мисиков Виктор}

Казбекович - канд. мед. наук, ассистент кафедры неврологии факультета усовершенствования врачей ${ }^{1}$

\129110, г. Москва, ул. Щепкина, 61/2-10, Российская Федерация. Тел.: +7 (495) 6815610 E-mail:1901viktor@mail.ru

Степанова Елена

Александровна -

канд. мед. наук, врач рентгенолог отделения компьютерной томографии и магнитнорезонансной томографии'

\section{Остапчук Константин}

Александрович аспирант кафедры неврологии факультета усовершенствования врачей ${ }^{1}$

Сидорович Владимир Игоревич - клинический ординатор кафедры неврологии факультета усовершенствования врачей ${ }^{1}$

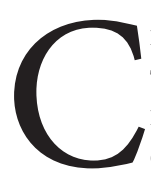
индром грушевидной мышцы характеризуется тоническим перенапряжением, что может приводить к компрессии элементов крестцового сплетения, включая седалищный нерв и нижнюю ягодичную артерию, в подгрушевидном пространстве, между мышцей и крестцово-остистой связкой. Клиническая картина складывается из локальной боли в нижней части ягодичной области в сочетании с ишиалгией - распространением боли по задней поверхности бедра при нагрузке. В тяжелых случаях возможно полное поражение седалищного нерва с развитием паралича мышц задней поверхности бедра и тотального паралича мышц голени и стопы [1].

Преимущественной причиной синдрома грушевидной мышцы, по данным отечественной литературы, считается дискогенная люмбоишиалгия. Зарубежные авторы среди этиологических факторов данного синдрома называют травму таза и мышц, хирургические вмешательства в области таза, объемные образования, аномалии развития мышцы, изменения тазобедренного сустава, а также спастичность и дистонию, которые могут встречаться в рамках детского церебрального паралича и при других заболеваниях центральной нервной системы. Диагностика синдрома грушевидной мышцы основана на пальпаторных тестах и тестах на растяжение. Дополнительно может использоваться электромиографическое исследование [2, 3].

Основным методом лечения синдрома грушевидной мышцы является ее инъецирование (или блокада) различными лекарственными средствами. Задолго до появления в клинической практике современных методов нейровизуализации в нашей стране был внедрен метод, основанный на введении лекарственного вещества (местного анестетика) в мышцу с использованием внешних ориентиров, который до сих пор широко используется в практике неврологов и нейрохирургов [4]. Приводим его схему и описание (рис. 1) [5]. Пациент располагается на кушетке на животе. Определение точки инъекции в грушевидную мышцу производят, выявив точки - ориентиры: заднюю верхнюю ость подвздошной кости, седалищный бугор и большой вертел бедра. Ориентиры соединяют линиями, образуя треугольник. Из вершины угла от задней верхней ости опускают биссектрису, которую условно делят на три части. Место инъекции определяют на границе между нижней и средней третями биссектрисы. При этом иглу вводят вертикально вниз на глубину 5-6 см до ощущения сопротивления, оказываемого крестцово-остистой связкой, после чего иглу извлекают на 0,5-1 см направляют вверх под углом $30^{\circ}$, в результате игла попадает в толщу грушевидной мышцы.

Анализируя данный метод, мы совместили его схему с костями задней поверхности таза и получили существенное несовпадение между локализацией мышцы и точкой для инъекции. Как видно на рис. 2, имеется существенное расхождение 


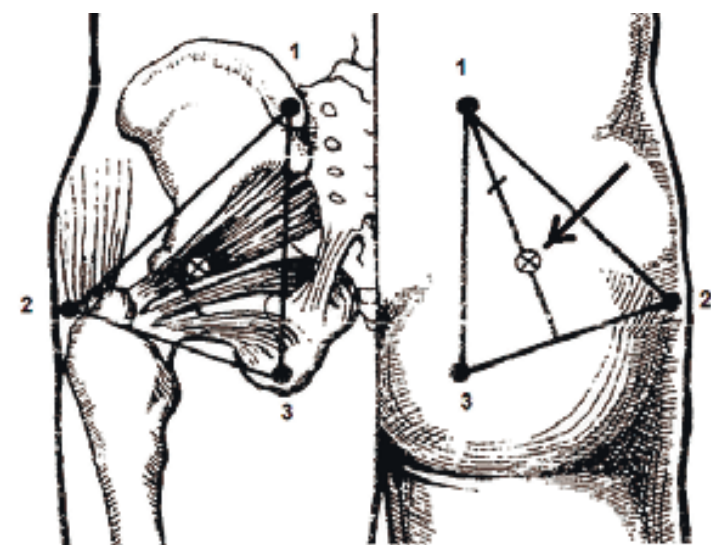

Рис. 1. Традиционная схема определения расположения грушевидной мышцы (Источник [5], с изменениями): 1 - верхняя задняя ость подвздошной кости, 2 - большой вертел бедренной кости, 3 - седалищный бугор. Место инъекции справа обозначено стрелкой

между истинной областью расположения мышцы и тем местом, которое определяется по костным ориентирам. Предлагаемая точка входа для блокады располагается в области проекции головки бедренной кости, и выполнение инъекции в грушевидную мышцу из данной точки весьма проблематично, если не невозможно.

Поскольку в настоящее время стало доступно большое количество руководств по рентгеновской компьютерной томографии (РКТ) и магнитно-резонансной томографии (МРТ), мы сравнили предлагаемую схему с данными, приведенными Т.Б. Меллером и Э. Райфом (2010) [7]. Представленный на рис. 3 срез проходит через головку бедренной кости. При анализе изображения становится понятной сложность инъецирования грушевидной мышцы, используя только внешние ориентиры. Отметим, что на указанном уровне размер грушевидной мышцы весьма невелик, она прикрыта многослойной подушкой ягодичных мышц, а в непосредственной близости, вплотную прилегая к ней, расположено крестцовое сплетение.

При анализе анатомических структур, расположенных на срезах различных уровней, был выбран срез, изображенный на рис. 4. На этом срезе, расположенном выше предыдущего, видны анатомические структуры таза, причем объем грушевидной мышцы на данном уровне существенно больше, сосудистые и нервные структуры не прилежат непосредственно к мышце. Несмотря на то что слой ягодичных мышц на этом уровне

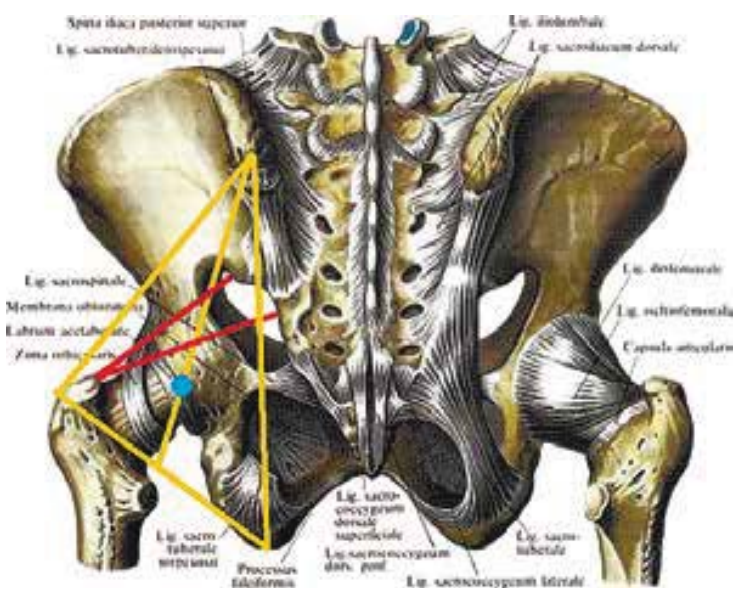

Рис. 2. Анатомия костно-связочных структур тазовой области (Источник [6], с изменениями]. Желтыми линиями соединены костные ориентиры. Голубая точка - область инъекции, рекомендуемая согласно методу использования внешних ориентиров. Красными линиями обозначены верхний и нижний края грушевидной мышцы

достаточно велик, в данном случае возможность для инъецирования мышцы лучше, а подход более безопасен.

Приводим описание клинического случая.

Больной И. 57 лет поступил в неврологическое отделение ГБУЗ МО МОНИКИ им. М.Ф. Владимирского с жалобами на постоянные ноющие боли в левой ягодичной области, усиливающиеся при движениях и иррадиирующие по задней поверхности левой ноги, на ползание «мурашек» по наружному краю левой стопы. Пациент отметил, что впервые боли возникли после чрезмерной физической нагрузки и беспокоят его уже несколько лет. Пациент периодически получал нестероидные противовоспалительные препараты, а также физиотерапевтическое лечение без значительного эффекта. При повторных магнитно-резонансных исследованиях пояснично-крестцовой области не обнаружено значимого снижения высоты или пролабирования межпозвонковых дисков (рис. 5).

При неврологическом осмотре выявлено: болезненность точки выхода левого седалищного нерва в ягодичной области, снижение левого ахиллова рефлекса. При пальпации левой ягодичной области глубинно прощупывался болезненный мышечный тяж. Пациент устойчиво стоял на пятках, но не мог стоять на носке левой ноги. Выявлена гипестезия по наружной поверхности левой стопы. Таким образом, клинически определялись признаки радикулопатии корешка S1, причем по данным МРТ признаков вертеброгенной компрессии корешков L5 и S1 не обнаружено.

Пациенту поставлен диагноз «синдром грушевидной мышцы. Невропатия левого седалищного нерва». 


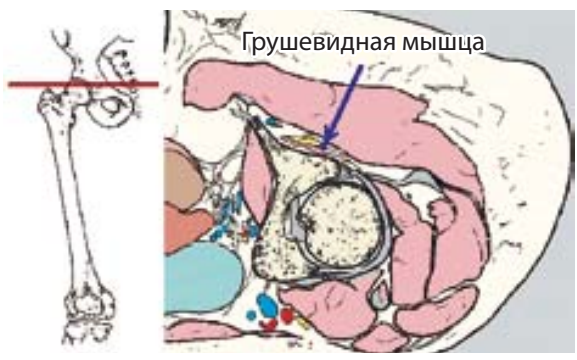

Рис. 3. Срез анатомических структур таза, проходящий через головку бедренной кости (Источник [7], с изменениями]. Слева схематическое расположение среза (красная линия), справа - анатомические структуры. Грушевидная мышца указана синей стрелкой
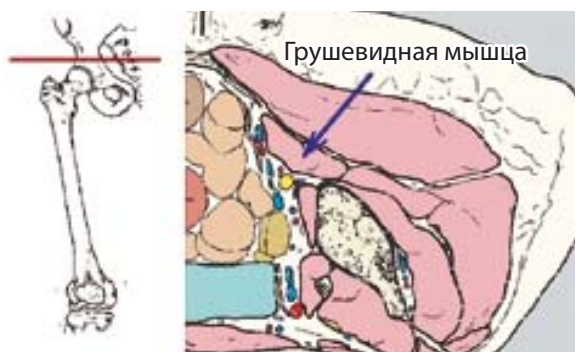

Рис. 4. Срез анатомических структур таза, проходящий выше вертлужной впадины (Источник [7], с изменениями]. Слева схематическое расположение среза (красная линия), справа - анатомические структуры. Грушевидная мышца указана синей стрелкой

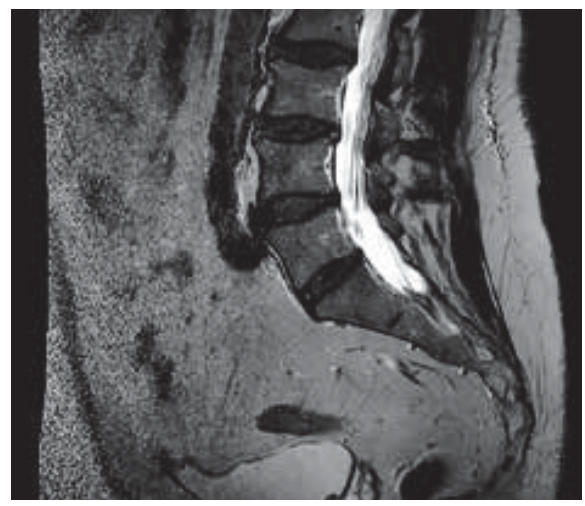

Рис. 5. МРТ пояснично-крестцового отдела позвоночника пациента $И$
В связи с длительным течением болевого синдрома было решено провести введение ботулотоксина для ликвидации болезненного спазма грушевидной мышцы, приводящего к компрессии седалищного нерва. Для проведения инъекции ботулотоксина в грушевидную мышцу под контролем РКТ выбран уровень, соответствующий отображенному на рис. 4. В процессе выполнения РКТ области таза получено изображение, аналогичное срезу из атласа Т.Б. Меллера и Э. Райфа [7] (рис. 6А). С использованием нейровизуализации выбраны направление введения иглы и оптимальная глубина инъекции - 55-60 мм (рис. 6Б). Для проведения ботулинотерапии использовали комплекс ботулинического токсина типа A - гемагглютинин. После введения препарата его локализация в толще грушевидной мышцы была подтверждена с помощью визуализации РКТ (рис. 7).

Далее мы проанализировали соотношение точек введения для блокирования грушевидной мышцы, полученное по внешним ориентирам и с использованием метода визуализации РКТ. Оказалось, что расхождение между полученными точками для инъекции составило 6,5 cм.
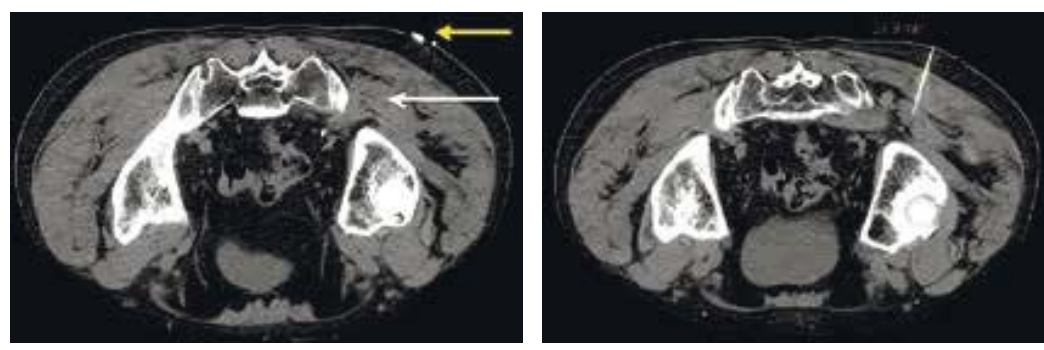

A

b

Рис. 6. РКТ пациента И. до лечения: А - белой стрелкой обозначена грушевидная мышца, желтой - металлический маркер на коже ягодичной области; Б - видна металлическая игла, погруженная в толщу грушевидной мышцы, глубина инъекции 57,9 мм
Спустя 5 суток после проведенной процедуры пациент отметил значительное уменьшение болей, прекращение парестезий. Через 2 недели произошло полное прекращение болей. После выписки из стационара пациенту проведен курс реабилитации, включавший лечебную физкультуру и физиотерапевтическое лечение. При осмотре через 4 месяца болевой синдром отсутствовал, болезненности в ягодичной области и по ходу седалищного нерва не выявлено.

Данное клиническое наблюдение не только иллюстрирует высокую эффективность ботулинотерапии при синдроме грушевидной мышцы, но и указывает на наличие большого числа заболеваний, приводящих к болям в нижнем отделе спины, что подчеркивает важность своевременной и полноценной диагностики у пациентов, приходящих к врачу с жалобами на боли в пояснице.

\section{Заключение}

Использование рутинных методов для определения локализации глубоких мышц не является точным и безопасным. Так, при нахождении

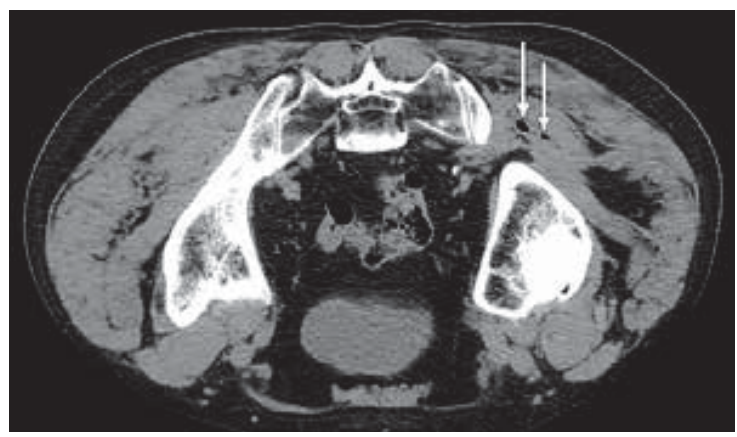

Рис. 7. РКТ пациента И. после введения ботулотоксина. Стрелками обозначены пузырьки препарата в толще мышцы 
точки инъекции грушевидной мышцы по наружным ориентирам высок риск как непопадания в мышцу, так и повреждения окружающих образований, в том числе сосудисто-нервных пучков. Очевидно, что для проведения инъекций глубоких слоев мышц в различных областях человеческого тела должны использоваться современные методы нейровизуализации - РКТ и ультразвуковое сканирование мягких тканей. Дополнительная функциональная диагностика в виде электромиографического исследования также облегчит правильность выбора места инъекции и позволит оценить функциональное состояние мышцы.

Сегодня, когда на смену недостаточно эффективным и краткосрочным по лечебному действию лечебным блокадам местных анестетиков приходят введения высокоэффективных препаратов длительного действия (эффект однократного введения ботулотоксина сохраняется до 3-4 месяцев), проведение таких процедур без современных методов технического контроля становится недопустимым. (⿻)

\section{Литература}

1. Гусев ЕИ, Бурд ГС, Никифоров АС. Неврологические симптомы, синдромы, симптомокомплексы и болезни. М.: Медицина; 1999. 169 с.

2.Кипервас ИП. Туннельные синдромы. М.: Ньюдиамед; 2010.520 с.

3. Бразис П, Мэсдью Дж, Биллер Х. Топическая диагностика в клинической неврологии. М.: МЕДпресс-информ; 2009. 735 с
4. Жулев НМ, Лобзин ВС, Бадзгарадзе ЮД. Мануальная и рефлекторная терапия в вертеброневрологии. СПб.; 1992. 586 с.

5. Тер-Вартаньян СХ, Яременко ОБ, Худина ВС. Локальная инъекционная терапия при поражениях суставов и периартикулярных тканей. Практическое руководство. Киев: Книга+; 1997. 142 с

\title{
References
}

1.Gusev El, Burd GS, Nikiforov AS. Nevrologicheskie simptomy, sindromy, simptomokompleksy i bolezni [Neurological symptoms, syndromes, syndromal clusters and disorders]. Moscow: Meditsina; 1999. 169 p. (in Russian).

2. Kipervas IP. Tunnel'nye sindromy [Tunnel syndromes]. Moscow: N'yudiamed; 2010. 520 p. (in Russian).

3. Brazis PW, Masdeu JC, Biller J. Topicheskaya diagnostika $v$ klinicheskoy nevrologii [Localization in clinical neurology]. Transl. from

English. Moscow: MEDpress-inform; 2009. 735 p. (in Russian).

4.Zhulev NM, Lobzin VS, Badzgaradze YuD. Manual'naya i reflektornaya terapiya $v$ vertebronevrologii [Manual and reflexory therapy in vertebral neurology]. Saint Petersburg; 1992.586 p. (in Russian).

5. Ter-Vartan'yan SKh, Yaremenko OB, Khudina VS. Lokal'naya in"ektsionnaya terapiya pri porazheniyakh sustavov i periartikulyarnykh tkaney. Prakticheskoe rukovodstvo [Local injectable therapy in joint

\section{Neuroimaging during botulinum toxin therapy}

\author{
Misikov V.K. • Stepanova E.A. • Ostapchuk K.A. • Sidorovich V.I.
}

We describe a clinical case of a piriformis syndrome in a patient with lumboischialgia. A technique of botulinum toxin therapy is described which was performed under neuroimaging control, i.e., with pelvic computerized tomography, that allowed for an accurate injection of the botulinum toxin into the deeply located muscle. Insufficient accuracy in determination of the injection site based on external reference points was shown.

Key words: piriformis syndrome, computerized tomography, botulinum toxin.
6. Синельников РД, Синельников ЯР. Атлас анатомии человека. 2-е изд. Т. 1. М.: Медицина; 1996. $344 \mathrm{C}$

7. Меллер ТБ, Райф Э. Атлас секционной анатомии человека. На примере КТ- и МРТ-срезов. Т. 3. М.: МЕДпресс-информ; 2010. с. 126-9.

and periarticular tissue disorders. A practical guide]. Kiev: Kniga+; 1997. 142 p. (in Russian).

6. Sinel'nikov RD, Sinel'nikov YaR. Atlas anatomii cheloveka [Atlas of human anatomy]. 2nd ed. Vol. 1. Moscow: Meditsina; 1996. 344 p. (in Russian).

7. Moeller TB, Reif E. Atlas sektsionnoy anatomii cheloveka. Na primere KT- i MRT-srezov [Pocket atlas of sectional anatomy. Computed tomography and magnetic resonance imaging]. Transl. from English. Vol. 3. Moscow: MEDpress-inform; 2010. p. 126-9 (in Russian).
Misikov Viktor Kazbekovich - PhD, Assistant, Chair of Neurology, Postgraduate Training Faculty ${ }^{1}$ $\triangle$ 61/2-10 Shchepkina ul., Moscow, 129110, Russian Federation. Tel.: +7 (495) 6815610. E-mail:1901viktor@mail.ru

Stepanova Elena Aleksandrovna - PhD, Radiologist, Department of Computer Tomography and Magnetic Resonance Imaging ${ }^{1}$

Ostapchuk Konstantin Aleksandrovich - Postgraduate Student, Chair of Neurology, Postgraduate Training Faculty'

Sidorovich Vladimir Igorevich - Resident, Chair of Neurology, Postgraduate Training Faculty ${ }^{1}$

Moscow Regional Research and Clinical Institute (MONIKI); 61/2 Shchepkina ul., Moscow, 129110 , Russian Federation 